\title{
Influence of crossover methods used by genetic algorithm-based heuristic to solve the selective harmonic equations (SHE) in multi-level voltage source inverter
}

\author{
SANGEETHA $\mathrm{S}^{1, *}$ and S JEEVANANTHAN ${ }^{2}$ \\ ${ }^{1}$ Department of Electrical and Electronics Engineering, Jawaharlal Nehru \\ Technological University, Hyderabad 500 085, India \\ ${ }^{2}$ Department of Electrical and Electronics Engineering, Pondicherry Engineering \\ College, Pondicherry 605 014, India \\ e-mail: sangeetha.hk@gmail.com; drsj_eee@pec.edu
}

MS received 2 November 2014; revised 7 May 2015; accepted 6 June 2015

\begin{abstract}
Genetic Algorithms (GA) has always done justice to the art of optimization. One such endeavor has been made in employing the roots of GA in a most proficient way to determine the switching moments of a cascaded $\mathrm{H}$-bridge seven level inverter with equal DC sources. Evolutionary techniques have proved themselves efficient to solve such an obscurity. GA is one of the methods to achieve the objective through biological mimicking. The extraordinary property of crossover is extracted using Random 3-Point Neighbourhood Crossover (RPNC) and Multi Midpoint Selective Bit Neighbourhood crossover (MMSBNC). This paper deals with solving of the selective harmonic equations (SHE) using binary coded GA specific to knowledge based neighbourhood multipoint crossover technique. This is directly related to the switching moments of the multilevel inverter under consideration. Although the previous root-finding techniques such as $\mathrm{N}-\mathrm{R}$ or resultant like methods endeavor the same, the latter offers faster convergence, better program reliability and wide range of solutions. With an acute algorithm developed in Turbo $\mathrm{C}$, the switching moments are calculated offline. The simulation results closely agree with the hardware results.
\end{abstract}

Keywords. Multilevel inverter; selective harmonic elimination; genetic algorithm; neighbourhood crossover.

\section{Introduction}

Technological advancement in power electronics has led into invention, improvisation, and utilization of multilevel inverters (MLI) in a competent and useful way. Of the many configurations available for MLI, cascaded H-bridge multilevel inverter (CHBMLI) is proved superior due to its simple structure, better control strategies and abridged protection circuits (Lai \& Peng

*For correspondence 
1996). The structure of CHBMLI proposed by Baker \& Bannister (1975) is celebrated more and more due to its capacity to operate at higher voltages. It is especially suitable for high power applications as the structure promises lower switching losses coupled with low electromagnetic interference (EMI) and less voltage harmonic content (Lai \& Peng 1996; Tolbert et al 1999; Rodriguez et al 2002; Zhong Du et al 2006). This converter with several DC sources also exhibits the superior quality of synthesizing a voltage waveform near stepped wave (Zhong Du et al 2004). The feat of MLI depends on the selection of modulation strategies. Ample modulation methods like sinusoidal PWM, space vector modulations, and their counterparts proposed over the years have combined the aim of achieving quality output with lesser harmonic content suitable for specific inverters applications (Ramkumar et al 2009; Pinheiro et al 2002; Hava et al 1998; Kirlin et al 2002). These deterministic methods have always succeeded in producing the required results. But these methods operate at high switching frequencies to achieve their motive of good efficiency and a fit spectrum (Samadi \& Farhangi 2007). The same reason could be the root cause for high switching losses which makes these methods a wrong candidate to attain the objective. Optimized switching angle methods like selective harmonic elimination pulse width modulation (SHEPWM) method proposed by Patel \& Hoft $(1973,1974)$ would be an ideal choice to support the purpose. These stepped wave methods operate at fundamental frequency to coalesce the objective of attaining the required output voltage with reduced harmonic spectrum (Jin Wang et al 2005; Zhong Du et al 2008).

SHEPWM has been considered as a predetermination method without carrier, with quarterwave symmetry idea. This variation has been proposed by Bhagwat \& Stefanovic (1983). The method demands the solving down of non-linear transcendental trigonometric equations desirable to determine the switching moments obtained through Fourier series expansion. Copious numerical methods like Newton-Raphson, sequential homotopy calculation, Walsh function method, Resultant theory, and symmetry polynomial method have lucidly solved these derived set of equations in a more rational and elaborate way (Jagdish Kumar et al 2008; Eryong Guan et al 2005; Liang et al 1997; Chiasson et al 2005). These mathematical methods are proved effective and often arrive at required switching moments to obtain the required fundamental voltage and also eliminate or reduce level of specific harmonics.

Although they offer amicable solutions, each method has their own short comings compared to another. The Newton method requires a good knowledge on the initial guess value to attain a good convergence of the roots. Homotopy algorithm based solutions are quite complicated and do not offer optimum solutions. Walsh functions are analytical, based on piecewise constant basis. The theory of resultants and symmetric polynomials postulated by Chiasson though interesting suffers from stretched procedures. Also when the parameters to be estimated increases, the time needed for calculation too increases. Since these deterministic methods suffer from the one hitch to another, heuristic methods gathered importance over the years. Some of these stochastic methods are ant colony optimization (ACO) (Sundareswaran et al 2007), particle swarm optimization (PSO) (Yamada \& Nakano 1997), genetic algorithm (GA) (Hagh et al 2009) and harmony search algorithm (HSA) (Hosseini \& Shahmohammadi 2012). As for ACO method it faces the problem of complexity in coding delayed convergence and probability distribution change during iterations. PSO demands good population strength and continuous iterations to achieve the required or near required results.

The concept of GA was introduced by Schutten and Torrey for the purpose of power electronics (Schutten \& Torrey 1995). Support can be obtained with its own theoretical and empirical formulas (Man et al 1996). Papers on hybrid combinations suffer the problem of restricted modulation index (Said Barkati et al 2008). Papers have also clearly indicated the improvement of $\%$ THD using the integrated method for GA and evolutionary techniques (Jeevananthan 2007). 
Many papers have been published with the concept of GA specific to SHEPWM with reduced number of devices and possible combinations (Khaled El Naggara \& Tamer H Abdelhamid 2008; Burak Ozpineci et al 2004; Reza Salehi et al 2011). Earlier work shows how multipoint crossover can be effectively implemented with lesser trauma for CHMLI (Sangeetha \& Jeevananthan 2014). But the paper does not touch upon the elements of crossover operators. A more refined objective is derived to show (i) the effect of Multi Midpoint Selective bit Neighbourhood crossover operator (MMSBNC) performes better than Random 3-Point Neighbourhood Crossover (RPNC) in a more realistic manner to hunt for the required switching moments and to prove

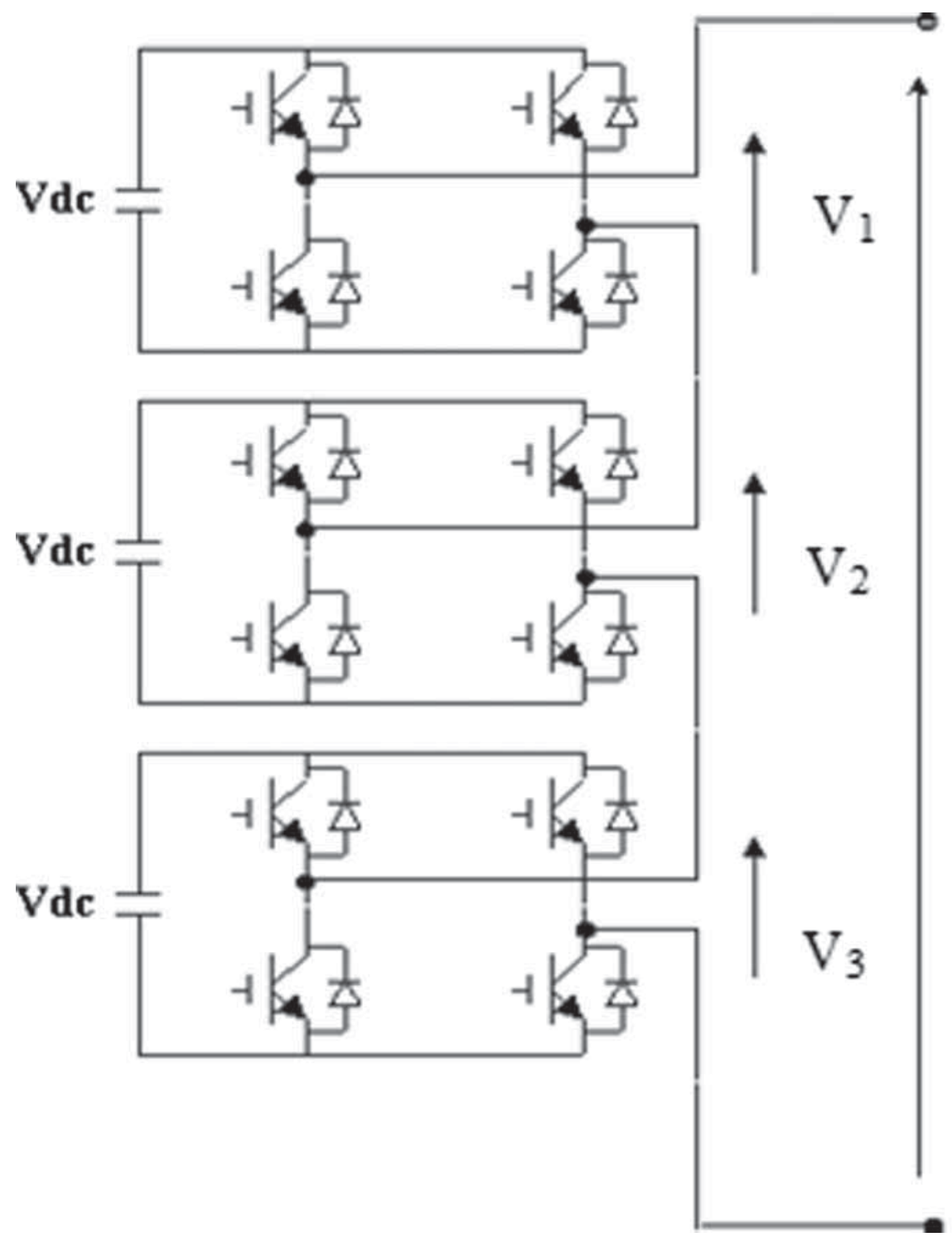

Figure 1. Structure of a seven level cascaded H-bridge inverter. 
that (ii) GA can yield better results when compared to formula based methods like resultant theory. The concept has been well tested using a Computational iterative algorithm which focuses on better convergence, non-multiple solutions (Switching Moments), good reduction of specific harmonics and \% THD ultimately. The simulated results and hardware results for the different profiles are presented.

\section{MLI and SHE equations}

\subsection{Cascaded MLI}

The cascaded MLI consists of several single-phase H-bridge inverters with separate dc sources is illustrated in figure 1 (Lai \& Peng 1996). The structure witnesses the avoidance of extra clamping diodes or voltage clamping capacitors (Zhong Du et al 2006). The output voltage waveform for a seven-level cascaded inverter is diagrammed in figure 2 with its synthesis. For a cascaded MLI, the number of output voltage levels, $m=2 S+1$, where ' $S$ ' is the number of dc sources. The output voltage is given by $V_{\mathrm{AB}}=V_{1}+V_{2}+V_{3}$.

The quarter wave symmetry of the wave makes the calculation procedure easy, as the cosine component and even order sine component do not exist. The key issue of elimination of lower order harmonics has been addressed in many ways. Prime importance is given to the same as they can reduce quality output, increase current ripple and torque pulsations (Chiasson et al

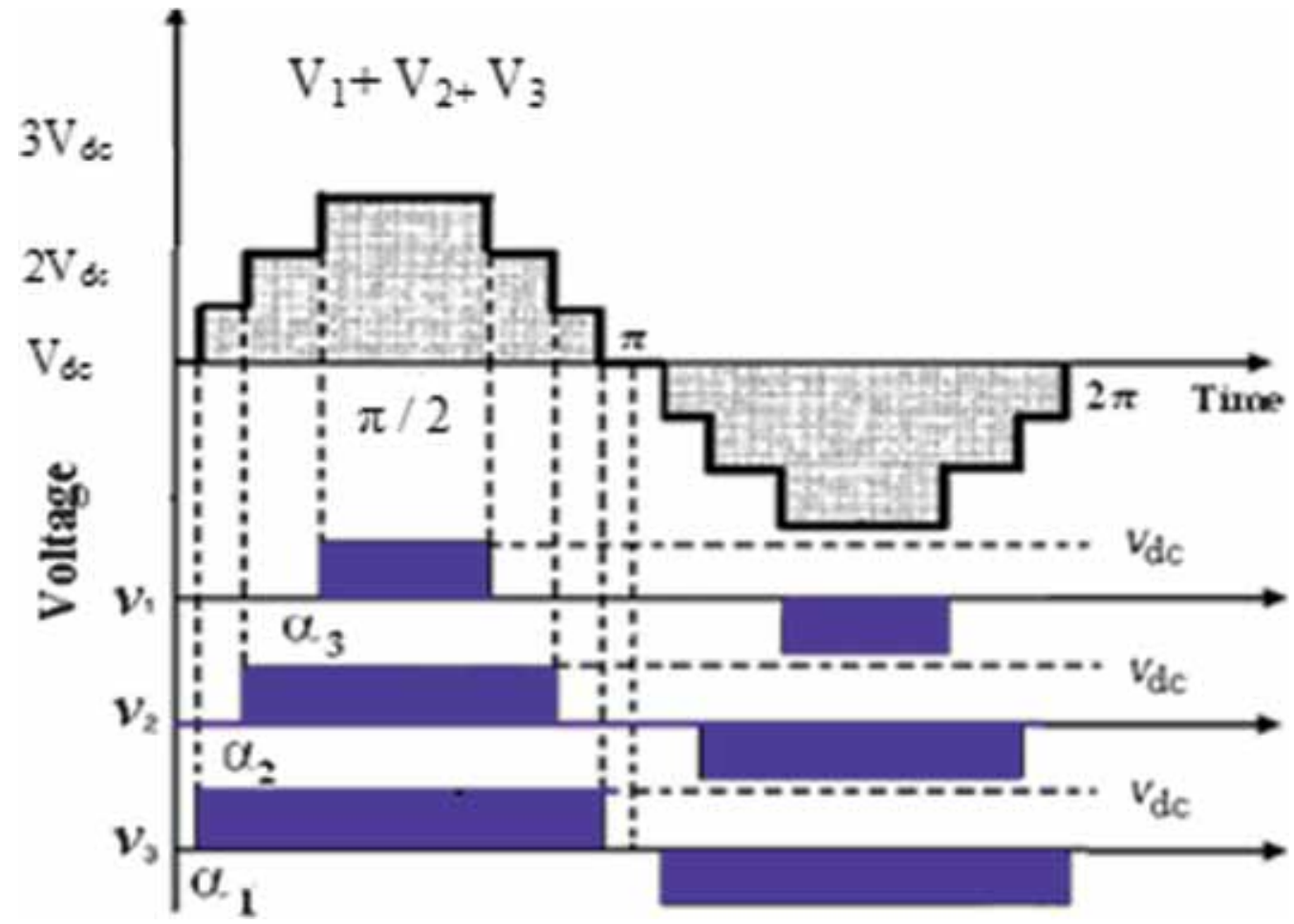

Figure 2. Output waveform of a seven level cascaded H-bridge inverter. 
Table 1. Switching states of cascaded seven level inverter.

\begin{tabular}{lcccc}
\hline Switching angle & $V \mathrm{a}_{1}$ & $V \mathrm{a}_{2}$ & $V \mathrm{a}_{3}$ & $V \mathrm{a}_{\mathrm{n}}$ \\
\hline $0 \leq \alpha_{1}$ & 0 & 0 & 0 & 0 \\
$\alpha_{1}<\alpha<\alpha_{2}$ & $V_{\mathrm{dc}}$ & 0 & 0 & $V_{\mathrm{dc}}$ \\
$\alpha_{2}<\alpha<\alpha_{3}$ & $V_{\mathrm{dc}}$ & $V_{\mathrm{dc}}$ & 0 & $2 V_{\mathrm{dc}}$ \\
$\alpha_{3}<\alpha<\pi / 2$ & $V_{\mathrm{dc}}$ & $V_{\mathrm{dc}}$ & $V_{\mathrm{dc}}$ & $3 V_{\mathrm{dc}}$ \\
\hline
\end{tabular}

2005). The switching instants, output of individual H-bridges and total output are presented in table 1.

\subsection{Mathematical derivation of the specific harmonic equation}

The real valued Fourier series of the (stepped) output voltage waveform of the multilevel inverter is written as

$$
v_{0}(\omega t)=a_{0}+\sum_{n=1}^{\infty} a_{n} \sin n \omega t+\sum_{n=1}^{\infty} b_{n} \cos n \omega t .
$$

Here $a_{0}$ is simply the $d c$ harmonic component. For periodic functions with half-wave symmetry $a_{0}=0$ and $b_{n}=0$ (for even $n$ )

$$
a_{n}=\frac{4 V_{d c}}{n \pi}\left[\cos n \alpha_{1}+\cos n \alpha_{2}+\cos n \alpha_{3}\right] .
$$

Substituting the values of $a_{o}, a_{n}$ and $b_{n}$, the instantaneous output voltage equation can be obtained.

$$
V_{0(\omega t)}=\frac{4 V_{d c}}{\pi} \sum_{n=1,3,5}^{\infty} \frac{1}{n}\left[\left(\cos n \alpha_{1}\right)+\left(\cos \left(n \alpha_{2}\right)+\left(\cos \left(n \alpha_{3}\right)\right] \sin n \omega t .\right.\right.
$$

The instantaneous voltage equation will help to make two objectives (i) To eliminate or minimize the lower order (S-1) odd harmonics from the output voltage waveform (ii) to control the output fundamental. It is worthwhile to note that the third objective of minimizing THD can be added if SHE problems are solved with optimization tools like GA (Schutten \& Torrey 1995; Said Barkati et al 2008). Where ' $n$ ' is the order of harmonics and it exists only for odd. For a given desired fundamental peak voltage $V_{1}$, it is required to determine the switching angles such that $0 \leq \alpha_{1}<\alpha_{2}<\ldots \alpha_{\mathrm{s}} \leq \pi / 2$. The single-phase seven-level MLI considered has three dc sources and the default eliminations are for third, fifth and seventh harmonics as they tend to dominate the spectrum. The switching angles are chosen in such a way that they eliminate the lower frequency harmonic and also that the THD is minimized. Instants $\alpha_{1}, \alpha_{2}$ and $\alpha_{3}$ in figure 2 represent a sample indication of optimal angles used in the proposed method with the condition $0 \leq \alpha_{1}<\alpha_{2}<\ldots \alpha_{\mathrm{s}} \leq \pi / 2$. Moreover, the relation between the fundamental component of the output voltage and the maximum obtainable fundamental component is (the value of the fundamental component obtained in fundamental switching) is termed as modulation index and is given as $m=V_{1} * \pi /\left(s * 4 * V_{\mathrm{dc}}\right)$.

$$
\begin{aligned}
\frac{4 V_{d c}}{\pi}\left(\cos \alpha_{1}+\cos \alpha_{2}+\cos \alpha_{3}\right) & =V_{1} \\
\left(\cos 3 \alpha_{1}+\cos 3 \alpha_{2}+\cos 3 \alpha_{3}\right) & =0 \\
\left(\cos 5 \alpha_{1}+\cos 5 \alpha_{2}+\cos 5 \alpha_{3}\right) & =0 \\
\left(\cos 7 \alpha_{1}+\cos 7 \alpha_{2}+\cos 7 \alpha_{3}\right) & =0 .
\end{aligned}
$$


The total number of harmonics to be eliminated is taken as two. It can be $3^{\text {rd }}$ and $5^{\text {th }}, 5^{\text {th }}$ and $7^{\text {th }}$ or $3^{\text {rd }}$ and $7^{\text {th }}$. To attain such an objective, a specific set of equations is to be formulated. The equations obtained by using the trigonometric identities are quite lengthy and contain many common terms. Down the line many methods have been proposed and successfully implemented for selective harmonic elimination (SHEPWM) to MLI topology, which may produce more than one solution set.

\section{Conventional genetic algorithm}

\subsection{Approximation versus heuristic methods}

This section explains the triumph of proven empirical formula methods over GA optimization techniques. In engineering and research, approximation algorithms have penetrated to the depth of optimization problem with a single scope to provide the best results. Successive linearization methods suffer certain drawback as compared to heuristic methods. The slag in these methods could be due to:

- High computational burden with higher order polynomials

- Yielding sub-optimal solutions

- Failure to obtain global convergence

- Algorithm may hit local minima

- Not applicable to all practical problems

- No decision oriented solutions

Heuristic means "experience-based techniques". Their stochastic nature enables them to employ specific random search mechanism to move from one set of solutions to another. The systematic search voids the change of getting entwined in the crater of local minima (Schutten \& Torrey 1995). There are multitudes of stochastic algorithms. One such method coupled with evolutionary process which allows the species to reproduce by the process of natural selection is GA (Man et al 1996; Beasley et al 1993; Goldberg 1989). It bangs the other algorithms due to its intelligent biological mimicking nature which guarantee exact switching instant to minimize or reduce harmonics (Herrera et al 2004; Khaled El Naggara \& Tamer H Abdelhamid 2008). The fit individual will have the ability to survive the environment and reproduce. GA is very co-operative in this domain as it reduces the cumbersome procedure of (a) predicting the initial guess values needed for optimization or (b) overcoming the exuberant procedure of solving the higher order polynomials to find the unknowns (Jagdish Kumar et al 2008; Chiasson et al 2005). GA is simple and is the direct solution for problems which require optimization (Goldberg 1989).

3.1a Genetic Algorithm as optimization method: Genetic algorithms have gained its importance in solving more and more challenges in power electronic industry (Burak Ozpineci et al 2004). Initially proposed by Holland (1992) and later developed to its mature form by David Goldberg (1989). GA's are classy algorithms which provide best solutions to optimization problem through the process of guessing. These controlled random search algorithms have been very lucrative in solving tribulations pertaining to SHE in CHBMLI's.

3.1b Design of genetic algorithm: The flexibility of the genetic algorithm solutions majorly lies with the problem under consideration. It is a computer based search algorithm, which relies 
on genetic mechanism of biological organisms. The solution it yields is efficient to out beat other stochastic techniques. The entire random search procedure is criteria-oriented (i.e.) based on the boundary condition to calculate the fitness value. The mathematical process either aims at maximization or minimization of the output as the case may be. Figure 3 represents the pictorial representation of Genetic Algorithm process. GA runs through generations. The initial step begins with the generation of the chromosomes which forms the random population within the boundary conditions. The population count is set to some random number. This is done through an iterative procedure based on some convergence criteria. The so selected samples are representative of the chromosomes. They can be encoded as either binary or real valued numbers. The fitness value of the samples is calculated so that the best and the worst are ranked in chronological order. Ranking method of selection has proved to yield appropriate results (Whitley 1989). The new population is created based on selection procedure. The selection procedure completes the ceremony of choosing the best sample and clubbing it with the other highperformance sample. Based on the crossover probability eligible chromosomes then undergo

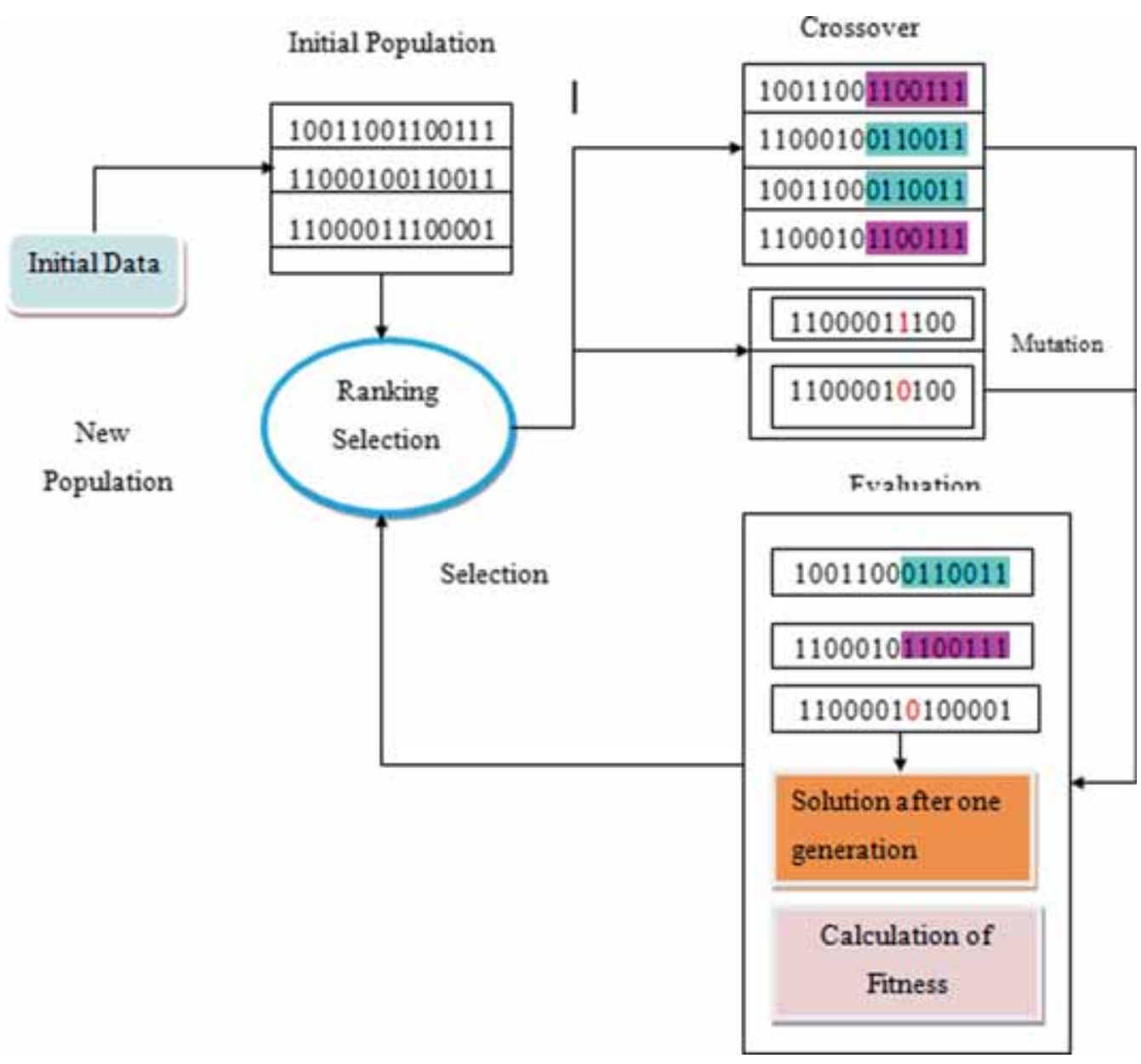

Figure 3. Pictorial representation of genetic algorithm process. 


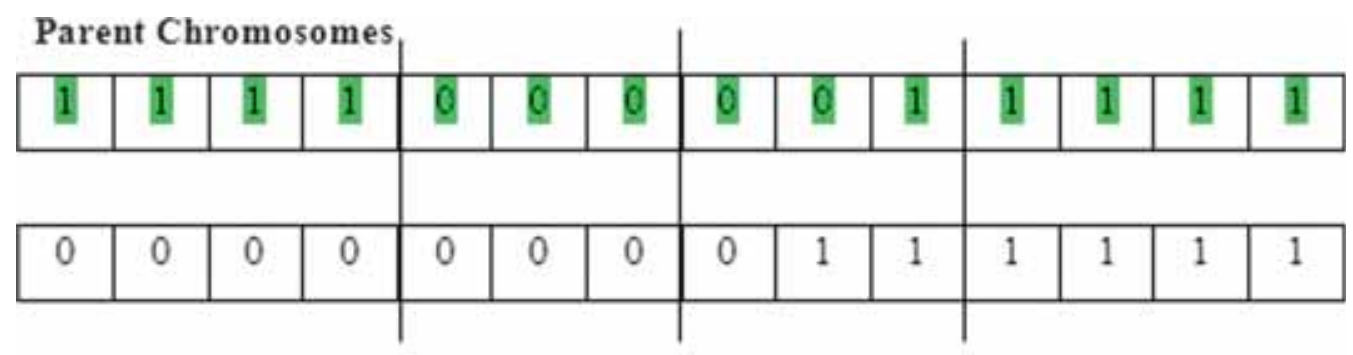

Child Chromosomes
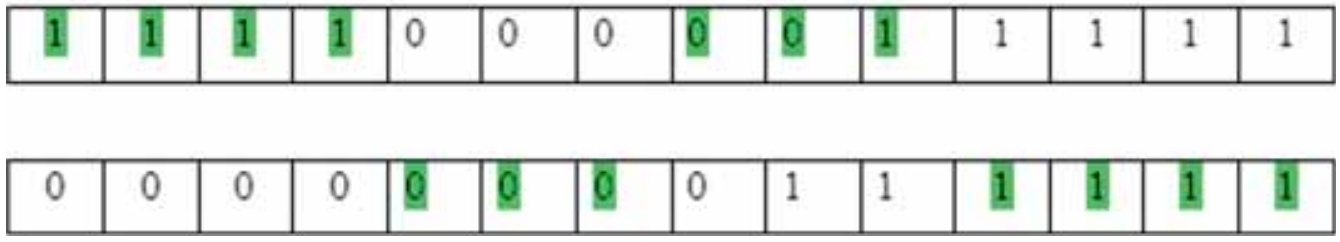

Figure 4. Pictorial representation of n-point crossover.

crossover to produce the new offspring. If there is no reproduction, the offspring will be exact copy of the parents. With mutation probability, a suitable locus is identified for the exchange of the gene information in a single chromosome. Mutation enables premature convergence and stimulates the optimization technique to be highly unearthing. This phenomenon ends up in production of new offsprings which are placed in the population pool to run the algorithm further. The algorithm comes to a stop when the stopping criterion is reached; else it starts once again with the calculation of the fitness function.

3.1c Significance of crossover and mutation: The main idea of performing the operators of crossover and mutation is to produce new individuals. The new offsprings are expected to perform better than their parents in the search space. In the process of crossover, the different traits of the chromosomes are swapped between the parents as per the crossover probability $(\mathrm{Pc})$. It controls the rate of crossover. Usually, it is set at a higher rate as compared to the mutation probability (Pm). Crossover operator can be single-point, two-point or uniform crossover. Figure 4 shows the pictorial representation of n-point crossover. In a single point crossover, the distribution bias is not taken care off. Eselman et al proposed the multipoint crossover, DeJong \& Spears (1990) were able to give more insight into the effect later Michalewicz (1994) too shared his ideas on the operator's efficiency (Spears \& DeJong 1991). Though it is proved that the efficiency of the new individuals is based on the crossover operator, even random n-point crossover at times will not produce the desired results. As compared with crossover operator, mutation is a more controlled operator with a lesser rate of probability as it can affect the complete trait of the chromosome leading to innovative offsprings. Only a combined planned combination of crossovers and mutation can deliver fit individual for the next generation.

\section{Multi-midpoint selective bit neighbourhood crossover genetic algorithm method}

Over the years, literature of GA states that crossover operator will definitely improve the fitness of the individual chromosomes. But planned crossovers will only yield desired results. In a 
n-point crossover the point of crossover is chosen randomly. They can be even or odd. The neighbourhood crossover chooses two parents which are close to each other in the objective space. When parents are chosen in random, there is a possibility of producing dominant offspring. In order to prevent it and to get into the grammar of exploitation and exploration, parents close to each other are chosen and crossed so that population does not suffer domination and consists of a diverse population. The procedure of neighbourhood population has the following steps to be carried out.

- All the individuals are sorted in order of proximity in the objective space

- The neighbourhood shuffle is done randomly to avoid local optima

- To select parents with close fitness to undergo crossover

GA is case specific and depends upon few factors. There are certain sequential steps to be followed while applying the optimization method. In this paper, invariably GA is employed for SHE PWM technique in a seven-level MLI. Before applying the algorithm, a basic design procedure is to be adopted (Goldberg 1989).

The basic sequential steps are:

a. Recognize the need for optimization (either for maximization or Minimization)

b. select the design variables which will augment efficiency and speed of the algorithm

c. Originate the constraints (boundary Conditions)

d. Formulate the objective Function

e. Apply GA

f. Attain best solution

\subsection{GA algorithm with multi midpoint selective bit neighbourhood crossover (MMSBNC)}

Neighbourhood crossover concentrates on choosing two fit parents close to each other in the Euclid space. This type of crossover fulfils the ceremony of crossover between proximal fit parents which are arranged in a particular ranking fashion. In this paper, two such cases are considered with respect to neighbourhood crossover bit selection. The basic backbone of the presentation is that by handling the bit position of crossover carefully and logically, an appreciable variation in the outcome namely the fitness function can be attained. As the population width is fixed, the playing method is only with the position of the bit in the string. Sorting and ranking (selection) aids in the choosing of the good (fit) parents as to avoid unnecessary non-dominant solutions.

\section{1a Sequential steps for MMSBNC GA program:}

(1) Selection of binary point strings

(2) The type of optimization is this problem will be minimization of the harmonics so, the inversion Function ' $\mathrm{f}$ ' is chosen so that cost function $\mathrm{f}\left(\alpha_{1}, \alpha_{2}, \alpha_{3}\right)=100 * \frac{\left|V_{5}\right|+\left|V_{7}\right|}{\left|V_{1}\right|}$

(3) The design variables for a seven-level inverter are chosen, so as to eliminate the specific harmonics. The three switching angle are $\alpha_{1}, \alpha_{2}, \alpha_{3}$.

(4) The size of the population is set to 20.

(5) The variables are subjected to boundary conditions. Here the boundary conditions of switching angle is between 0 and 90 degrees and that $0 \leq \alpha_{1}<\alpha_{2}<\alpha_{3} \leq 90^{\circ}$

(6) After the chromosome length has been calculated, in this case (42) the fitness is checked for all 20 eligible chromosomes generated randomly represented as " $\mathrm{M}$ " in the algorithm. The 


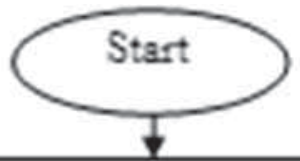

Formulate the fundamental and the hamonic equations. Fix the no of hamonics to be eliminated and their boundary conditions

Derive the fitness fomula. Here the cas e is minimization $f\left(\alpha_{2}, \alpha_{2}, \alpha_{3}\right)=100 \frac{|+|+||}{|| \mid}$

$$
t
$$

Fix the domain range and the length of the chromosome. Set the population size, $P_{f}$ and $P_{m}$. Set the decimal precision

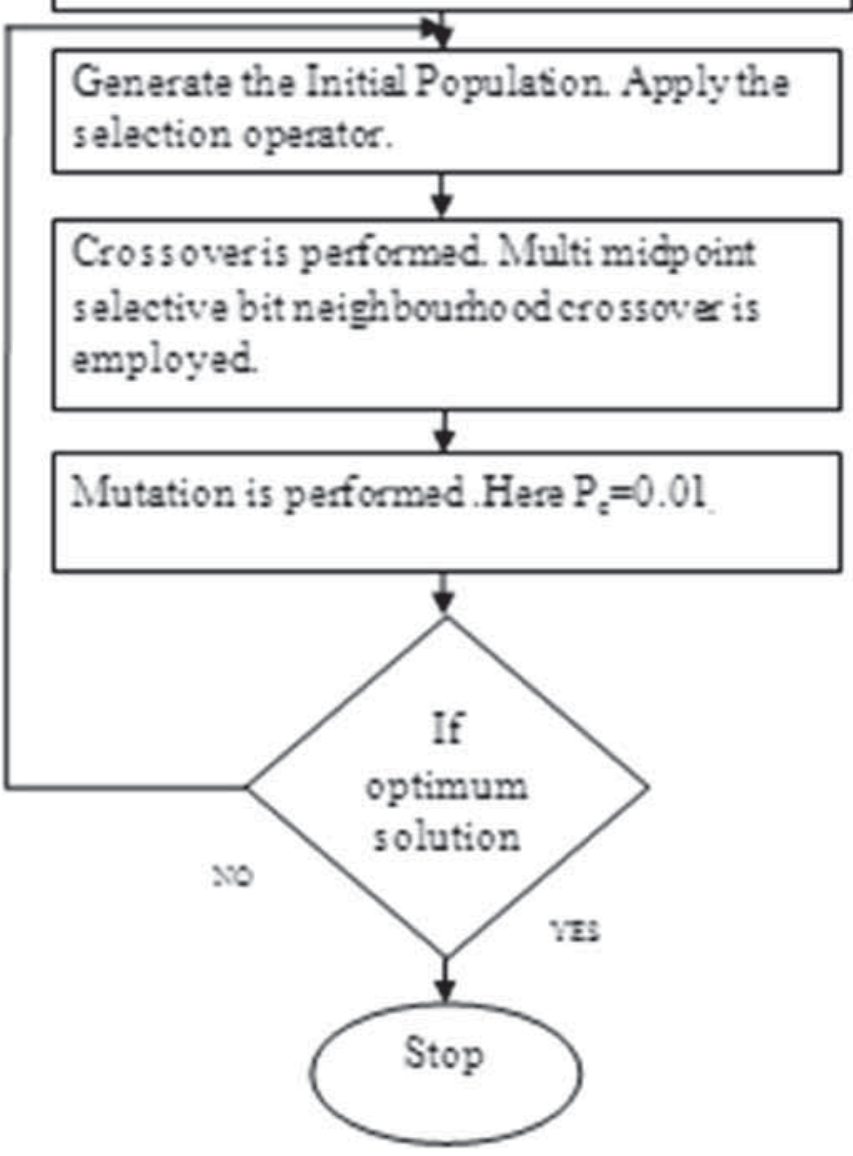

Figure 5. Flow chart for GA with MMSBNC method. 
paper deals with elimination of third, fifth and seventh harmonic combination. The fitness value is calculated as $\mathrm{f}\left(\alpha_{1}, \alpha_{2}, \alpha_{3}\right)=100 * \frac{\left|V_{5}\right|+\left|V_{7}\right|}{\left|V_{1}\right|}$

(7) This forms the fit parent matrix ready to reproduce.

\section{Parent 1: 100010101011}

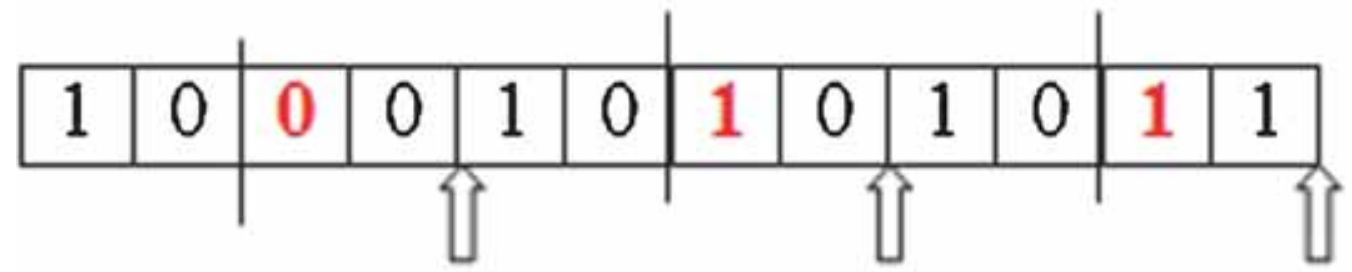

\section{Segment 1 Segment 2 Segment3}

Parent 2: 101100111100

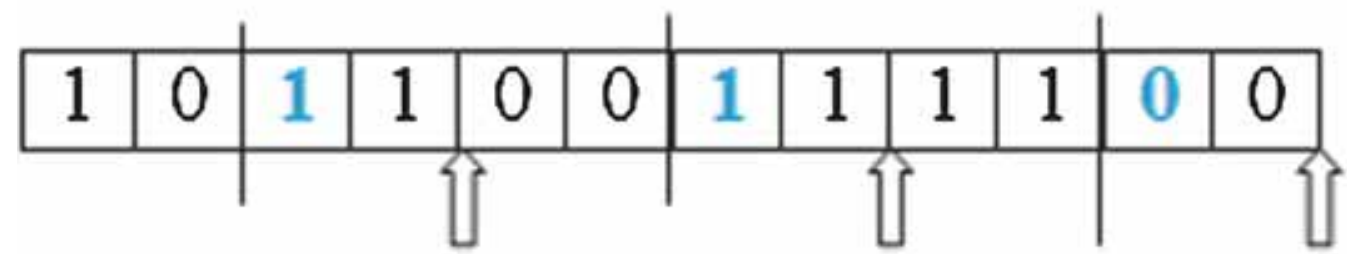

Segment 1 Segment 2 Segment3 Child 1:
1
0

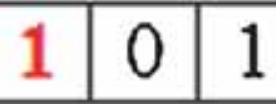
$0 \mid 1$
0
10
001

Child 2:

\begin{tabular}{|l|l|l|l|l|l|l|l|l|l|l|l|}
\hline 1 & 0 & 0 & 1 & 0 & 0 & 1 & 1 & 1 & 1 & 1 & 0 \\
\hline
\end{tabular}

Figure 6. Multi Midpoint Selective Bit Neighbourhood crossover (MMSBNC). 
Table 2. Multi Midpoint Selective Bit Neighbourhood Crossover (MMSBNC).

\begin{tabular}{ll}
\hline Pseudo code for crossover & Pseudo code for mutation \\
\hline $\begin{array}{l}\text { For } h=0 \text { to } \mathrm{M} / 2 \\
\text { randomly select two LSB bits of } \mathrm{X}_{\mathrm{A}} \text { and } \mathrm{X}_{\mathrm{B}}\end{array}$ & $\begin{array}{l}\text { For } h=0 \text { to } 7 \\
\mathrm{i}=\text { Select a random value between } 0\end{array}$ \\
$\begin{array}{l}\text { from Parent }(\mathrm{P}) \\
\text { generate } \mathrm{X}_{\mathrm{C}} \text { and } \mathrm{X}_{\mathrm{D}} \text { by crossover to } \mathrm{X}_{\mathrm{A}} \text { and } \mathrm{X}_{\mathrm{B}}\end{array}$ & $\begin{array}{l}\mathrm{j}=\text { Select a random value between } 0 \text { to } \\
41 / / \text { Total No. of bits in a String }(42)\end{array}$ \\
$\begin{array}{l}\text { if } X_{C} \text { and } X_{D} \text { is feasible } \\
\text { update } \mathrm{X}_{\mathrm{C}} \text { and } \mathrm{X}_{\mathrm{D}} \text { as new child }\end{array}$ & $\begin{array}{l}\text { Mutate the bit of } \mathrm{X}[\mathrm{i}][\mathrm{j}] \text { and generate new } \\
\text { child } \mathrm{X}^{\prime} / /(0 \text { becomes } 1\end{array}$ \\
end if & or becomes 0$)$ \\
end for & If $X^{\prime}$ is feasible \\
For $\mathbf{h}=\mathbf{M} / \mathbf{2}$ to $\mathbf{M}$ & update $\mathrm{X}^{\prime}$ as new child \\
randomly select two MSB bits of $\mathrm{X}_{\mathrm{A}}$ and $\mathrm{X}_{\mathrm{B}}$ & End if \\
from Parent $(\mathrm{P})$ & End for \\
generate $\mathrm{X}_{\mathrm{C}}$ and $\mathrm{X}_{\mathrm{D}}$ by crossover to $\mathrm{X}_{\mathrm{A}}$ and $\mathrm{X}_{\mathrm{B}}$ & \\
$\begin{array}{l}\text { If } X_{C} \text { and } X_{D} \text { is feasible } \\
\text { update } \mathrm{X}_{\mathrm{C}} \text { and } \mathrm{X}_{\mathrm{D}} \text { as new child }\end{array}$ & \\
End if & \\
End for & \\
\hline
\end{tabular}

(8) Checking of the fit chromosome is based on the individual value of switching angles and the calculation of the fitness function is based on the cost function.

(9) Once the fitness function is calculated they are ranked in the ascending order. The process of multi midpoint selective bit neighbourhood crossover is carried out. The bit selection is based on the best to worst fitness. Figure 5 indicates the flowchart.

(10) After obtaining the child chromosomes they are ranked and the new population matrix is formed.

(11) The ritual of mutation is done with $P_{\mathrm{m}}=0.01$ (i.e.) for the 840 bits of chromosomes available 8 bits are mutated. After each and every mutation the chromosomes are checked for eligibility. If found eligible the process is stopped otherwise proceeds to next mutation.

(12) Thus if required the process is completed eight times.

(13) Once the entire process is finished, the arrival of optimal solution is checked.

(14) If "yes" the algorithms comes to a halt. Else the entire steps are repeated sequentially until the optimal solution is arrived.

4.1b Example for MMSBNC process: Figure 6 Multi Midpoint Selective Bit Neighbourhood crossover - (MMSBNC) and table 2 indicate the pseudo-code for crossover and mutation operator.

\subsection{GA algorithm with random 3-point neighbourhood crossover (RPNC)}

The procedure adopted is quite similar to MMSBNC method. The change happens only in step (9) where RPNC is adopted. Figure 7 indicates the Random 3-Point Neighbourhood Crossover (RPNC). The process of bit crossing is indicated in the figures. Parents with three segments are chosen for example. In RPNC method the bits are chosen in a random fashion. In MMSBNC method, midpoint bit is chosen and crossing is performed. According to Spears \& DeJong (1991) sensible crossover always yields better children, resulting in better solutions. 


\section{Parent 1: 100010101011}

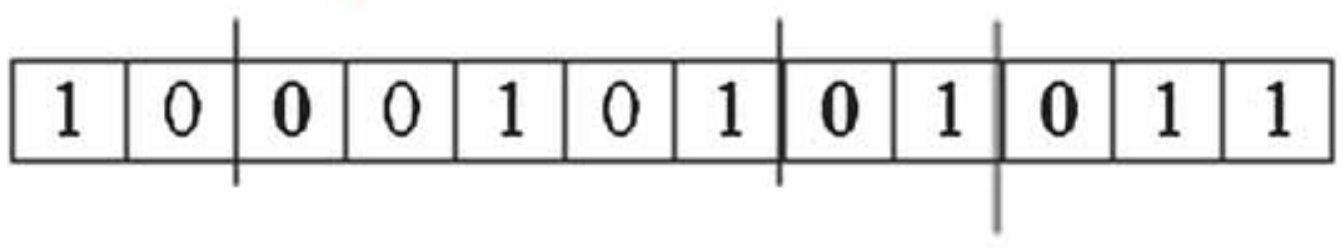

\section{Parent 2: 101100111100}

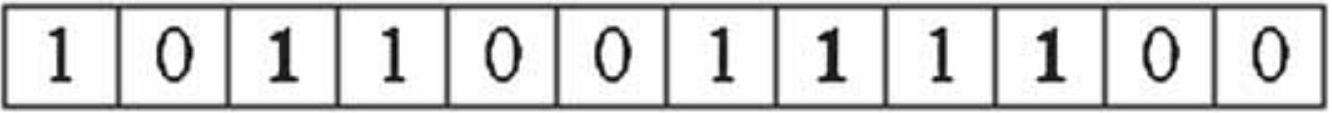

\section{Child 1:}

\section{\begin{tabular}{|l|l|l|l|l|l|l|l|l|l|l|l|}
1 & 0 & 1 & 0 & 1 & 0 & 1 & $\mathbf{1}$ & 1 & $\mathbf{1}$ & 1 & 1 \\
\hline
\end{tabular}}

Child 2:

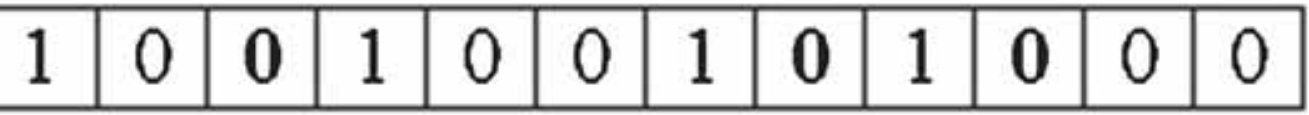

Figure 7. Random 3-Point Neighbourhood Crossover (RPNC).

Table 3. Comparison between RPNC and MMSBNC method.

\begin{tabular}{lccc}
\hline Algorithm & Computational time & $\begin{array}{c}\text { Space occupied during execution } \\
\text { (crossover operation) }\end{array}$ & $\begin{array}{c}\text { No. of steps to converge } \\
\text { for crossover operation }\end{array}$ \\
\hline RPNC method & $0.35 \mathrm{~S}$ & $9.52 \mathrm{~KB}$ & 31 \\
MMSBNC method & $0.41 \mathrm{~S}$ & $15.7 \mathrm{~KB}$ & 32 \\
\hline
\end{tabular}

\subsection{Effectiveness of MMSBNC over RPNC}

The developed program has been tested for both MMSBNC and RPNC methods. Based on the results obtained a few points can be understood. Since in MMSBNC method the bit crossing 
Table 4. Switching angle to obtain $5^{\text {rd }}$ and $7^{\text {th }}$ harmonic minimization.

\begin{tabular}{|c|c|c|c|c|c|c|c|c|}
\hline \multirow[t]{2}{*}{$\mathrm{m}$} & $\alpha_{1}$ & $\alpha_{2}$ & $\alpha_{3}$ & \multirow[t]{2}{*}{$V_{1}(\mathrm{p})$} & $V_{1(\mathrm{rms})}$ & $\% V_{5}$ & $\% V_{7}$ & \multirow[t]{2}{*}{$\% \mathrm{THD}$} \\
\hline & \multicolumn{3}{|c|}{ degrees } & & \multicolumn{3}{|c|}{$\% V_{1}$} & \\
\hline 1.8 & 11.01 & 40.18 & 85.72 & 115.3 & 81.54 & 0.04 & 0.61 & 18.32 \\
\hline 1.85 & 5.25 & 33.85 & 88.78 & 117 & 82.74 & 0.24 & 0.85 & 20.31 \\
\hline 2.1 & 16.05 & 41.99 & 64.59 & 135.1 & 95.54 & 0.94 & 0.08 & 19.74 \\
\hline 2.3 & 13.08 & 34.07 & 60.13 & 145.6 & 102.97 & 0.52 & 0.4 & 14.35 \\
\hline 2.4 & 13.57 & 22.73 & 55.04 & 156.2 & 110.46 & 0.55 & 0.68 & 14.14 \\
\hline 2.45 & 14.09 & 21.59 & 52.6 & 158.7 & 112.2 & 0.75 & 0.21 & 14.45 \\
\hline 2.50 & 13.98 & 22.22 & 53.98 & 157.1 & 111.10 & 0.41 & 0.67 & 14.16 \\
\hline
\end{tabular}

\section{Modulation Index Vs Fitness Function}

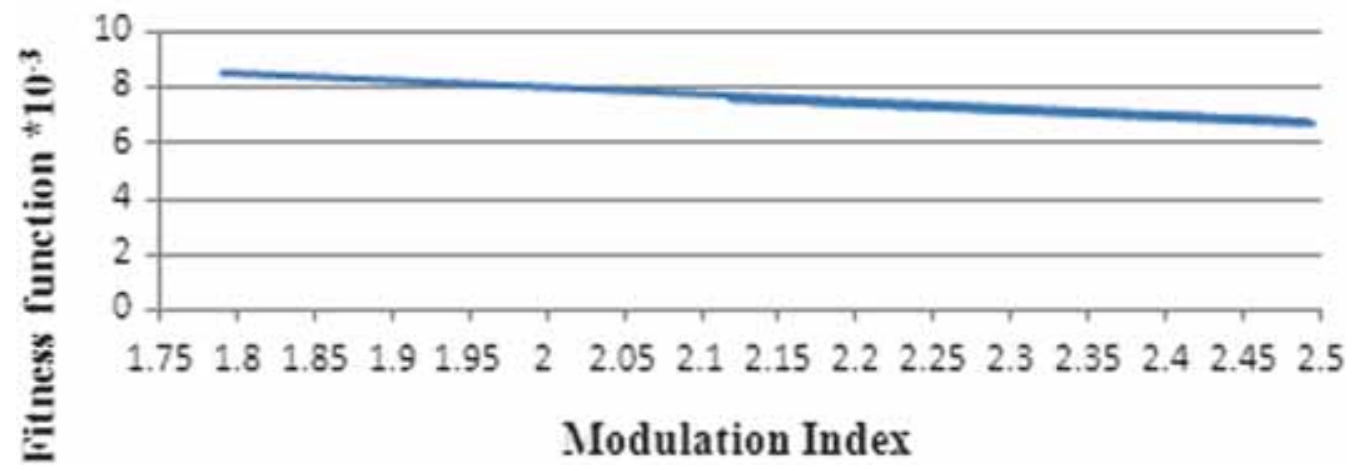

Figure 8. Modulation index Vs fitness function.

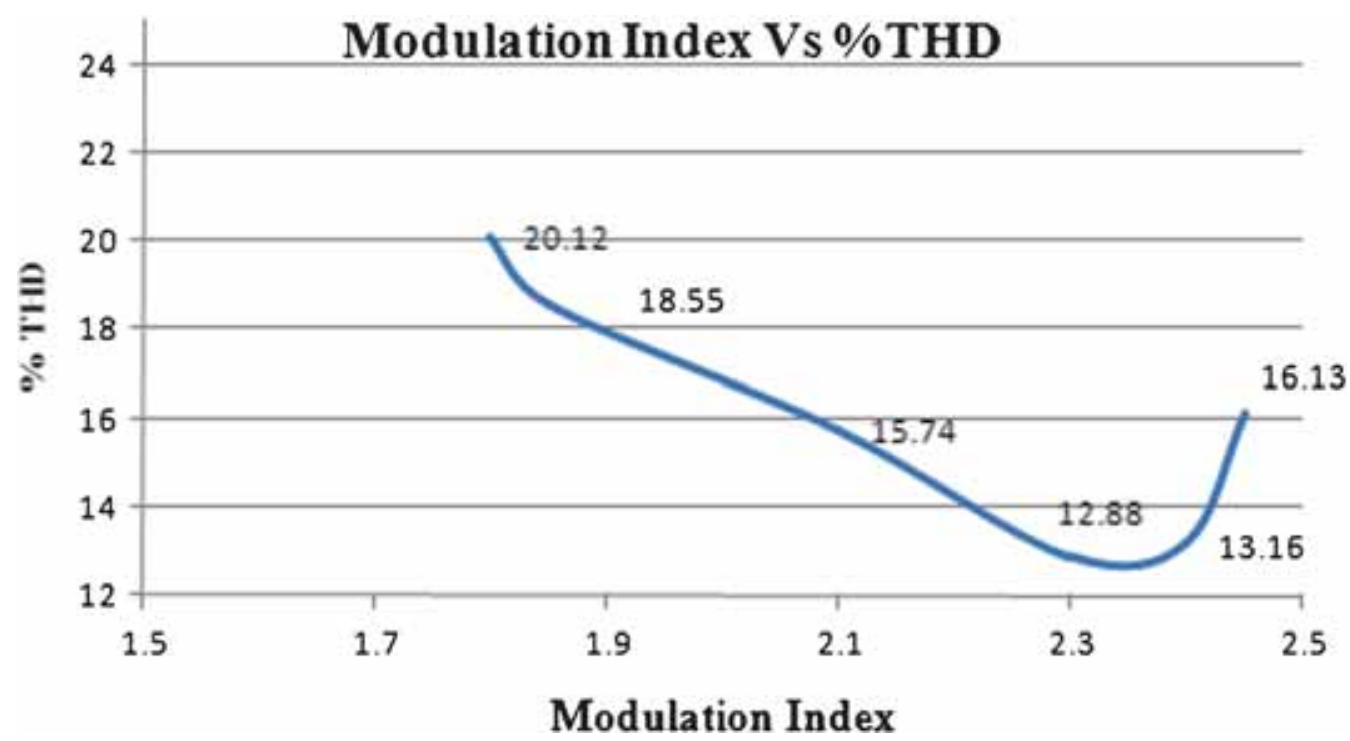

Figure 9. Modulation index Vs \%THD for RPNC method. 


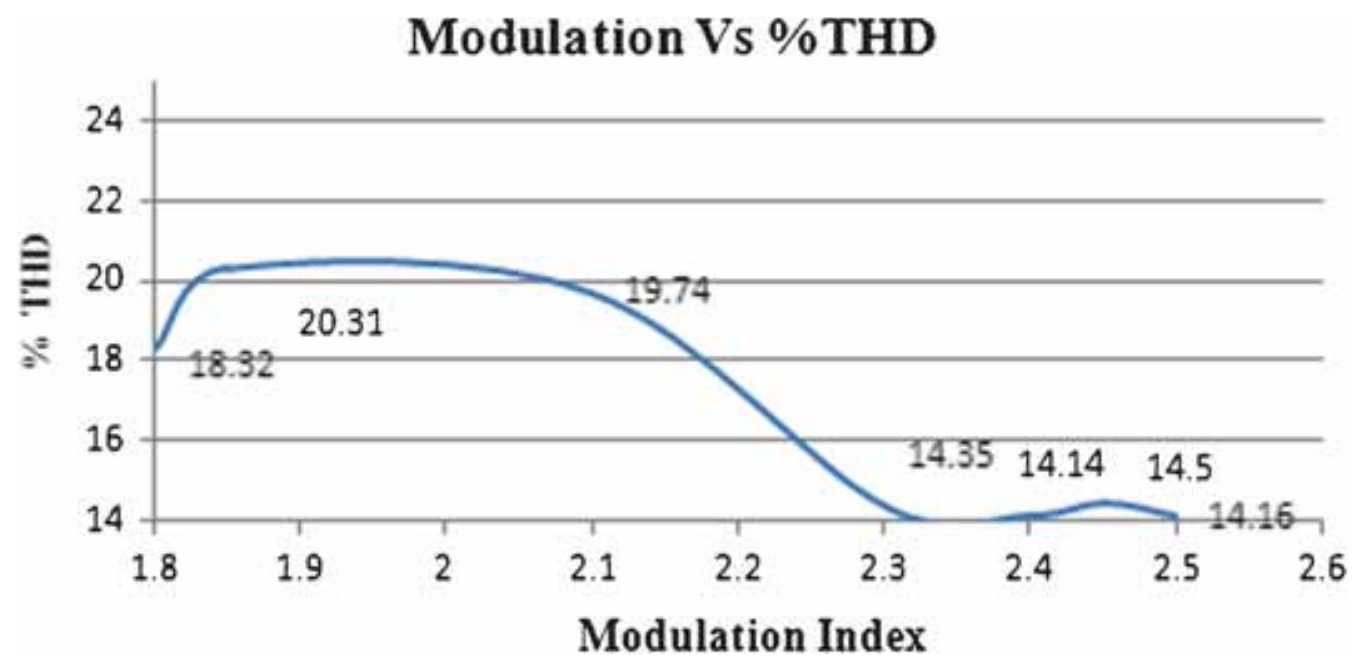

Figure 10. Modulation index Vs \%THD for MMSBNC method.

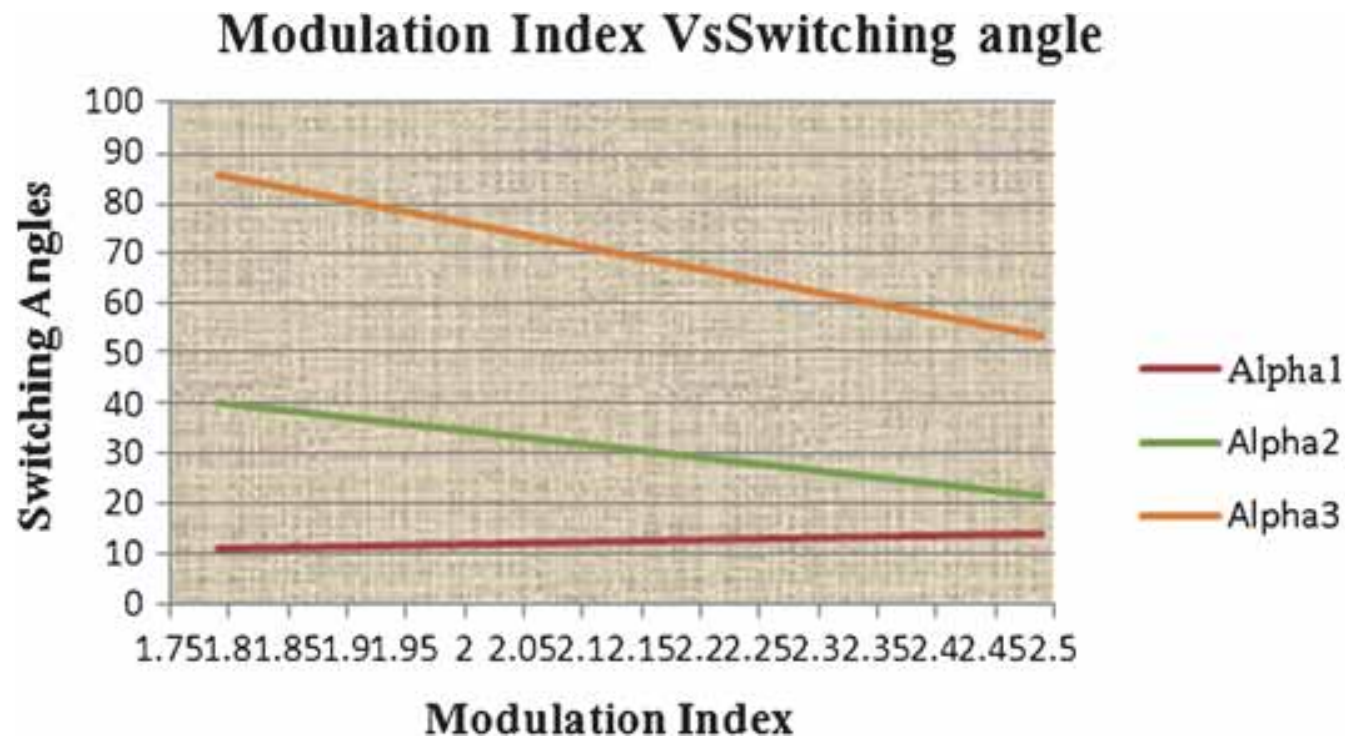

Figure 11. Modulation index Vs switching angle.

occurs evenly throughout the string (i) Data retrieved from fit parents is equally passed on to the offsprings too make it a fit child for the next generation

(ii) The point of crossover is distributed.

(iii) The rate of fitness value is uniform.

It is also analyzed in terms of

(i) Computational time

(ii) Space occupied during execution of crossover operation 


\section{Generation Vs Fitness Function}

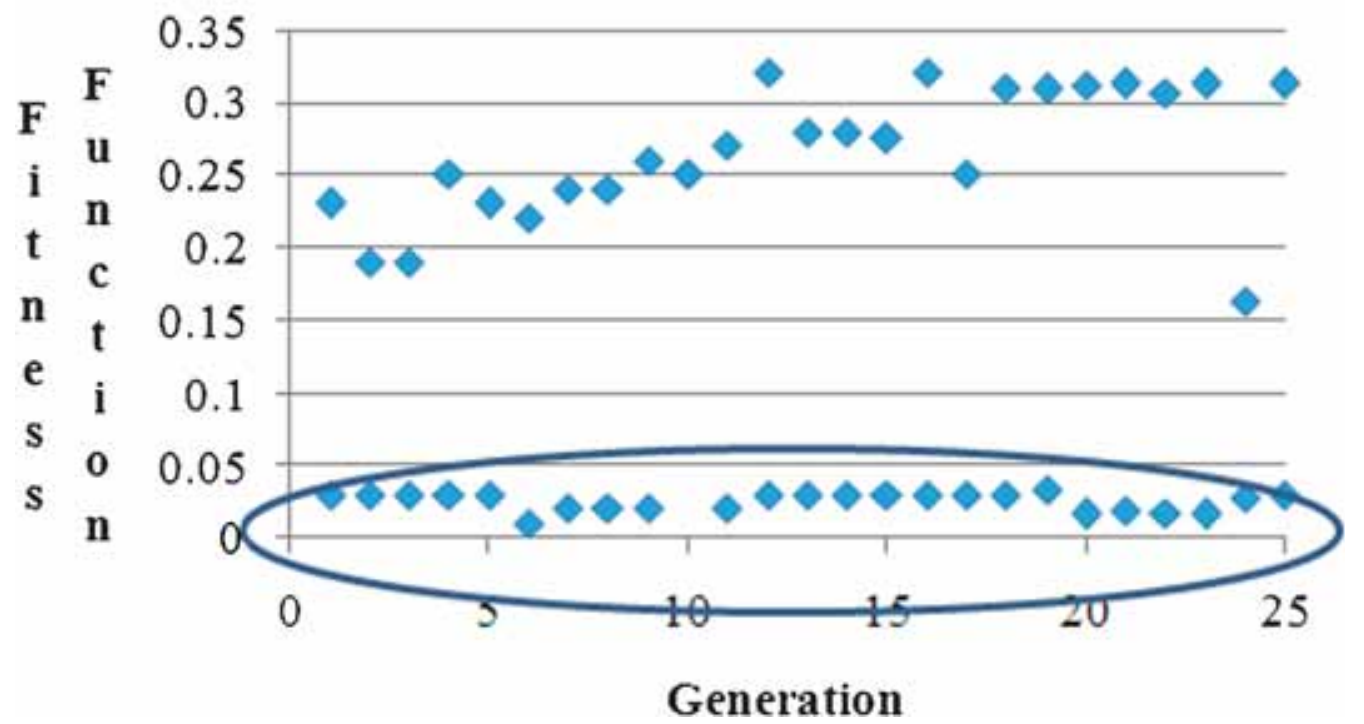

Figure 12. Generation versus fitness function.

Table 5. Variation of fundamental voltage to \% THD for the different methods.

\begin{tabular}{|c|c|c|c|c|c|}
\hline \multicolumn{2}{|c|}{ Resultant theory } & \multicolumn{2}{|c|}{ RPNC method } & \multicolumn{2}{|c|}{ MMSBNC method } \\
\hline Fundamental voltage & $\% \mathrm{THD}$ & Fundamental voltage & $\%$ THD & Fundamental voltage & $\% \mathrm{THD}$ \\
\hline 111.4 & 17.22 & 117.6 & 20.12 & 115.3 & 18.32 \\
\hline 117.8 & 38.52 & 117.2 & 18.55 & 117 & 20.31 \\
\hline 140.1 & 15.42 & 141.6 & 15.74 & 135.1 & 19.74 \\
\hline 146.4 & 11.74 & 148.9 & 12.88 & 145.6 & 14.35 \\
\hline 152.8 & 9.51 & 158.4 & 13.16 & 156.2 & 14.14 \\
\hline
\end{tabular}

Table 6. Variation of modulation index Vs specific harmonics and \%THD.

\begin{tabular}{lccccc}
\hline Modulation index & Method employed & $\mathbf{V}_{\mathbf{1}}(\mathbf{V})$ & $\mathbf{\% V}_{\mathbf{5}}(\mathbf{v})$ & $\mathbf{\%}_{\mathbf{7}}(\mathbf{V})$ & $\mathbf{\%} \mathbf{T H D}$ \\
\hline 1.8 & Resultant theory method & 111.4 & 1.22 & 0.43 & 17.22 \\
& RPNC method & 117.6 & 0.13 & 1.24 & 20.12 \\
& MMSBNC method & 115.3 & $\mathbf{0 . 0 4}$ & $\mathbf{0 . 6 1}$ & $\mathbf{1 8 . 3 2}$ \\
1.85 & Resultant theory method & 116.2 & 0.95 & 0.48 & 39.82 \\
& RPNC method & 117.2 & 1.12 & 0.85 & 18.55 \\
& MMSBNC method & 117 & $\mathbf{0 . 2 4}$ & $\mathbf{0 . 8 5}$ & $\mathbf{2 0 . 3 1}$ \\
2.3 & Resultant theory method & 146.4 & 0.09 & 0.01 & 11.74 \\
& RPNC method & 148.9 & 1.05 & 1.58 & 12.88 \\
& MMSBNC method & 145.6 & $\mathbf{0 . 5 2}$ & $\mathbf{0 . 4 0}$ & $\mathbf{1 4 . 3 5}$ \\
\hline
\end{tabular}

(iii) No. of steps to converge for crossover operation

System specification: Intel core i3CPU@2.27GHZ

Processor speed: 2.27 GHZ and memory 2 GB RAM 


\section{Fundamental Voltage Vs \% THD}

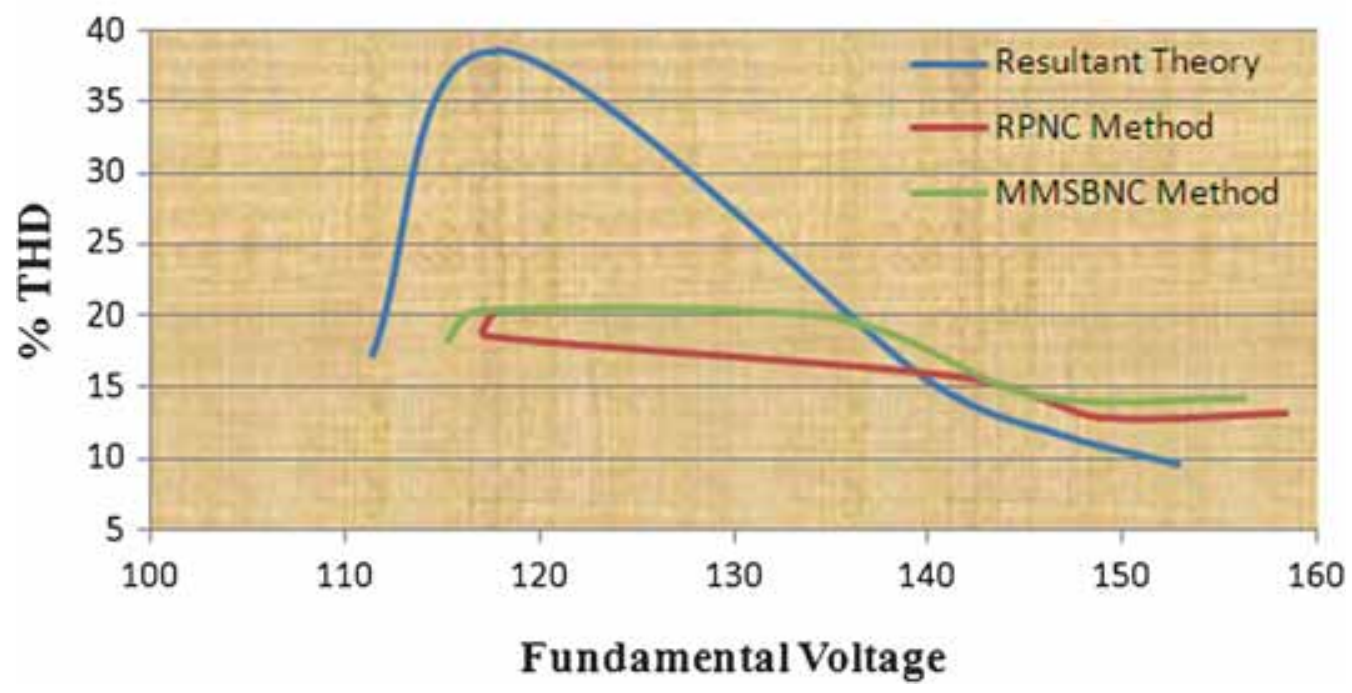

Figure 13. Fundamental voltage Vs \%THD.

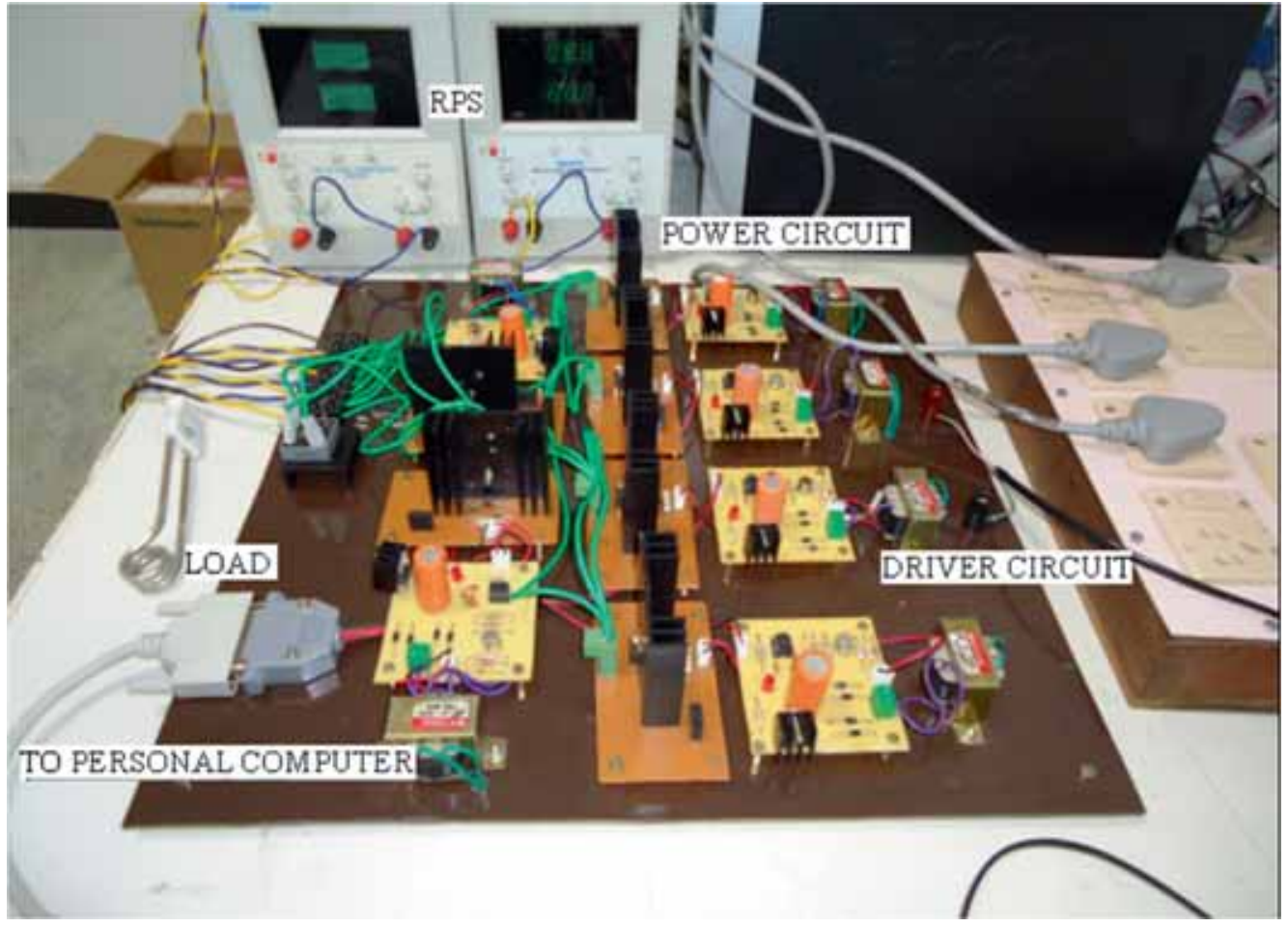

Figure 14. Photograph of the hardware setup. 
Table 3 indicates that in MMSBNC method since elaborate process takes place during crossover operation in the selection of the qualifying bit the space and the time to convergence is sufficiently high when compared to the RPNC method. As reduction in \% THD is also one of the objectives in this work better handling of the crossover operation is compulsory.

\section{Results and discussion}

\subsection{Simulation results}

The GA programme has been executed and the optimum triplen switching angles for minimization of $3^{\text {rd }}, 5^{\text {th }}$ and $7^{\text {th }}$ harmonics are calculated offline. The calculated switching angles also propose to reduce the \% THD. The simulation for seven-level cascaded H-Bridge has been done and the results are tabulated. Table 4 shows the switching angle to obtain $5^{\text {rd }}$ and $7^{\text {th }}$ harmonic minimization. Figure 8 shows the relationship between modulation index Vs fitness function. Figures 9 and 10 show the relationship between modulation index Vs \%THD for RPNC and MMSBNC method respectively. Figure 11 shows the relationship between modulation index Vs switching angle. Figure 12 shows the relationship between generation Vs fitness function. Table 5 shows the variation of fundamental voltage to \%THD for the different methods. Table 6 shows the variation of modulation index Vs specific harmonics and \%THD.

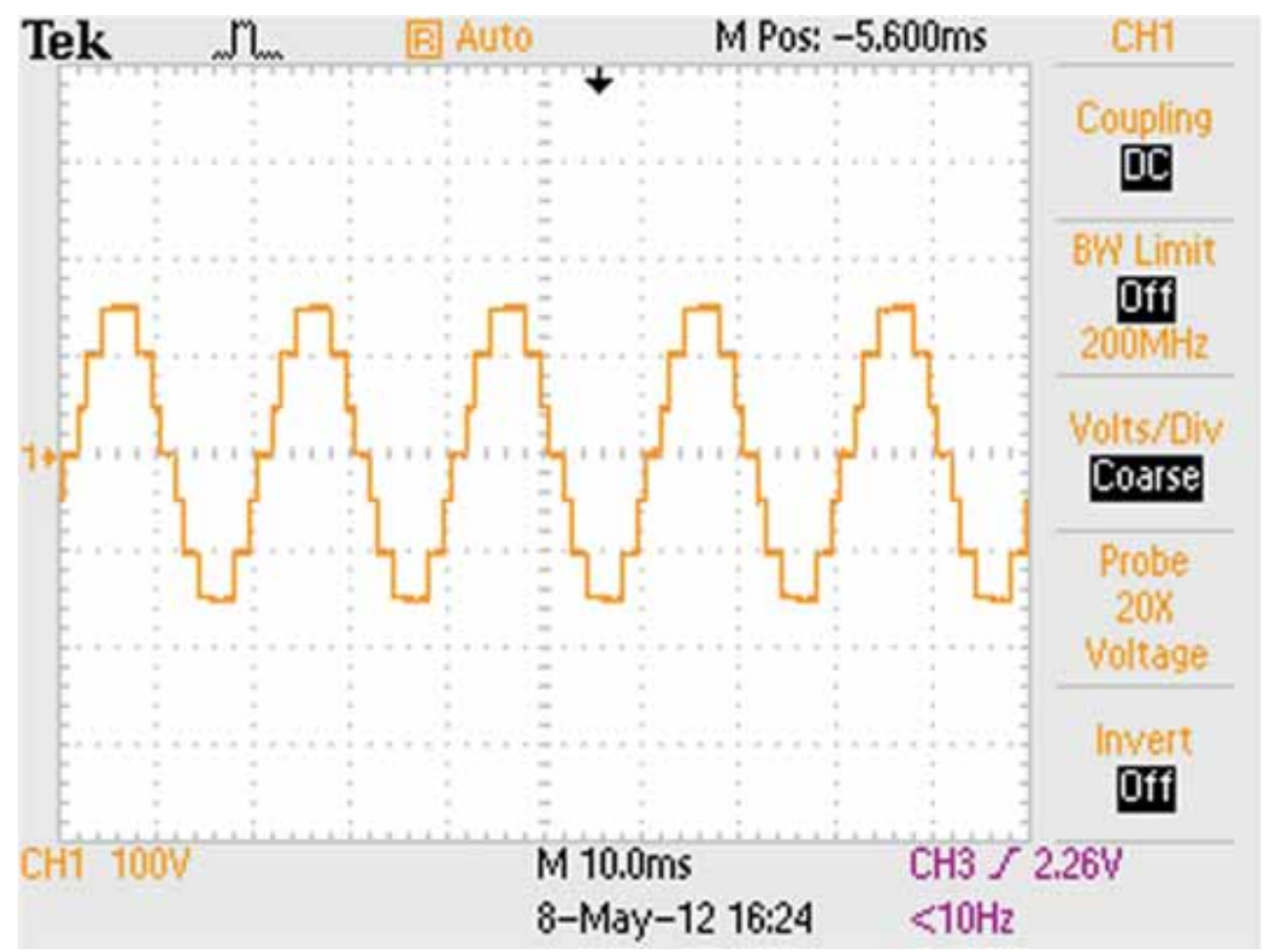

Figure 15. Output voltage waveform for R load. 

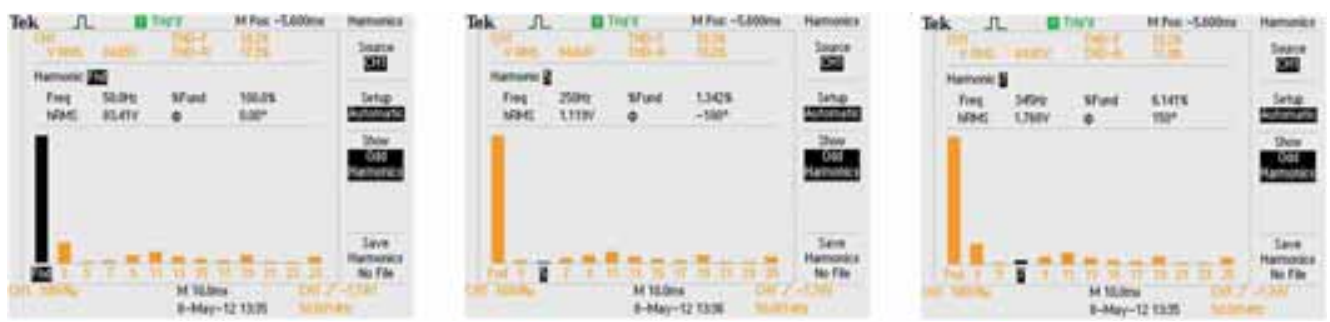

Figure 16. Harmonic spectrum of output voltage.

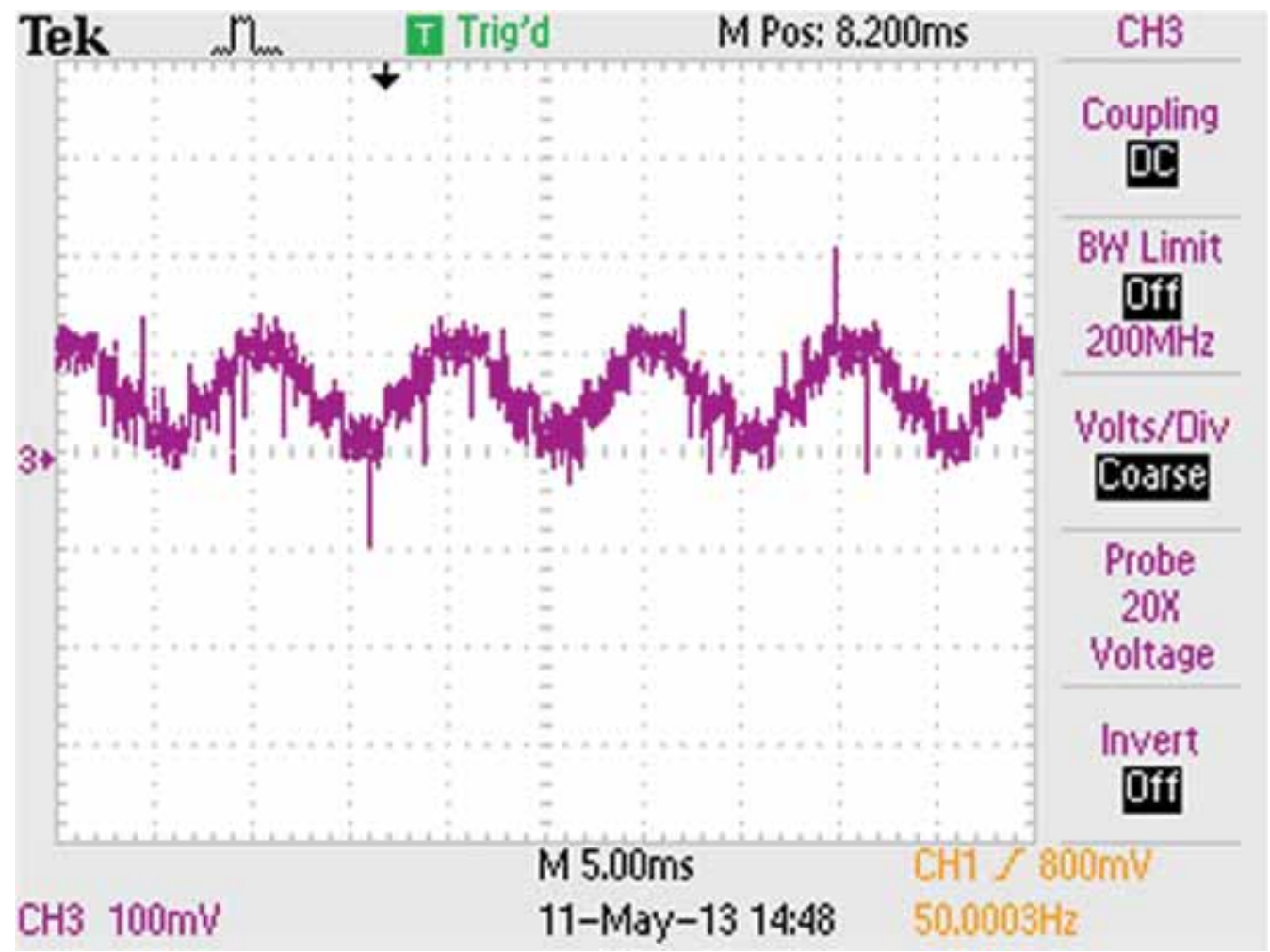

Figure 17. Harmonic spectrum of output current - RL load.

Figure 13 shows the relationship between fundamental voltage Vs \%THD for various methods.

\subsection{Hardware results}

An effort has been accomplished to design and fabricate a seven level inverter. It is shown in figure 14. The switching angles are calculated for different conditions. Real-Time Windows Target of MATLAB/Simulink is used to generate the gating pulses. The host computer needs only a virtual device driver to exchange parameters between MATLAB and Simulink memory space. The Virtual Reality Toolbox contains functions for using special hardware devices, including 
Table 7. Comparison of simulated and hardware results $(\mathrm{MI}=1.7)$.

\begin{tabular}{lcccc}
\hline $\begin{array}{l}\text { Methodology } \\
\text { (MMSSBNC) }\end{array}$ & $\begin{array}{c}\text { Fundamental } \\
\text { voltage }\end{array}$ & $\mathrm{V}_{3(\mathrm{~V})}$ & $\mathrm{V}_{7(\mathrm{~V})}$ & THD (\%) \\
\hline Simulation values & 78.63 & 0.41 & 0.67 & 14.16 \\
Hardware values & 83.41 & 1.19 & 1.76 & 18.2 \\
\hline
\end{tabular}

Joystick and space-Mouse. It connects the hardware devices using Simulink blocks. The separate dc voltages are set to $50 \mathrm{~V}$ and the resistive load is set to $100 \mathrm{ohms}$. MOSFETs IRF840 constitute the power module. The result for $5^{\text {th }}$ and $7^{\text {th }}$ harmonic elimination is studied in this section. The systematic digital generation of gating pulses is displayed vividly through channels 1-4 of the scope TPS2024. A sample of the output voltage is captured as seen in figure 15. The harmonic spectrum of output voltage output current is presented in figures 16 and 17 for $\mathrm{MI}=1.7$. The experimental results closely agree with the simulation results as seen in table 7 .

\section{Conclusion}

In this work, genetic algorithm optimization technique is applied to find the switching angles of the cascaded inverter for the reduction of harmonics. The results obtained show that fifth and seventh order harmonics are reduced effectively. GA based solution of switching angles gives minimum THD in the output voltage waveform compared with the conventional resultant theory method. As in this approach, GA can be applied to any type of optimization problems. GA reduces the harmonic content more predominantly than any other conventional technique such resultant theory and other mathematical methods available. This work can be extended by applying GA to reduce the harmonics in inverters with any number of levels. The hardware results are presented and it is found that these results agree with the simulation results.

\section{List of symbols}

$\alpha$, switching angle

$\pi$, maximum degree value

$\omega$, angular frequency

\section{References}

Baker R H and Bannister L H 1975 Electric power converters. U.S Patent 3 867: 643

Beasley D, Bull D R and Martin R R 1993 An overview of genetic algorithms Part 1: Foundations University. Computing 15(4): 170-181

Bhagwat P M and Stefanovic V R 1983 Generalized Structure of a Multilevel PWM Inverter. IEEE Transactions on Industrial Applications, vol. 1A- 19, pp. 1057-1069

Burak Ozpineci, Leon M Tolbert and John N Chiasson 2004 Harmonic optimization of multilevel converters using genetic algorithms. In: Proceedings of Power Electronics Specialists Conference, vol. 5, pp. 39113916 
Chiasson J N, Tolbert L M, McKenzie K J and Zhong Du 2005 Elimination of harmonics in a multilevel converter using the theory of symmetric polynomials and resultants. IEEE Trans. Control Syst. Technol. 13(2): 216-223

DeJong K A and Spears W M 1990 An analysis of the interacting roles of population size and crossover in genetic Algorithms. In: Proceedings of First Workshop Parallel Problem Solving from Nature, pp. 3847-3857

Eryong Guan, Pinggang Song, Manyuan Ye and Bin Wu 2005 Selective harmonic elimination techniques for multilevel cascaded H-bridge inverters. In: Proceedings of Power Electronics and Drives Systems, vol. 2, pp. 1441-446

Goldberg D E 1989 Genetic algorithms in search, optimization and machine learning. Addison-Wesley, Reading, MA

Hagh M T, Taghizadeh H and Razi K 2009 Harmonic minimization in multilevel inverters using modified species-based particle swarm optimization. IEEE Trans. Power Electron. 24(10): 2259-2267

Hava A M, Kerkman R J and Lipo T A 1998 A high-performance generalized discontinuous PWM algorithm. IEEE Trans. Ind. Appl. 34(5): 1059-1071

Herrera F, Lozano M and Sanchez A M 2004 Hybrid cross over operators for real - coded GA: Experimental Study, Springer-verlag Transactions on Soft Computing, pp. 281-300

Holland J H 1992 Adaptation in natural and artificial systems. MIT Press, Cambridge, MA

Hosseini S H and Shahmohammadi S 2012 A generalized optimization in cascade and modular multilevel inverters by harmony search method. In: Proceedings of 12th International Conference Control, Automation and Systems pp. 1506-1511

Jagdish Kumar, Biswarup Das and Pramod Agarwal 2008 Selective harmonic elimination technique for a multilevel Inverter. In: Proceedings of 15 National Power Systems Conference, pp. 608-613

Jeevananthan S 2007 Evolutionary computational based area integration PWM technique for multi level inverters. J. Electr. Syst. 61-72

Jin Wang, Yi Huang and Peng F Z 2005 A practical harmonics elimination method for multilevel inverters. In: Proceedings of Industry Applications Conference, vol. 3, pp. 1665-1670

Khaled El Naggara and Tamer H Abdelhamid 2008 Selective harmonic elimination of a new family of MLI using GA. Science Direct Transactions on Energy Conservation and Management 49: 89-95

Kirlin R L, Bech M M and Trzynadlowski A M 2002 Analysis of power and power spectral density in PWM inverters with randomized switching frequency. IEEE Trans. Ind. Electron. 49(2): 486-499

Lai J S and Peng F Z 1996 Multilevel converters - A new breed of power converters. IEEE Trans. Ind. Appl. 32: 509-517

Liang T J, O'Connell R M and Hoft R G 1997 Inverter harmonic reduction using Walsh function harmonic elimination method. IEEE Trans. Power Electron. 12(6): 971-982

Man K F, Tang K S and Kwong S 1996 Genetic algorithms: Concepts and applications. IEEE Trans. Ind. Electron. 43(5): 519-534

Michalewicz Z 1994 Genetic algorithms + data structures = evolution program. 2nd ed., Springer-Verlag

Patel Hasmukh S and Hoft R G 1973 Generalized techniques of harmonic elimination and voltage control in thyristor inverters: Part I-harmonic elimination. IEEE Trans. Ind. Appl. IA-9(3): 310-317

Patel Hasmukh S and Hoft R G 1974 Generalized techniques of harmonic elimination and voltage control in thyristor inverters: Part-II- voltage control techniques. IEEE Trans. Ind. Appl. IA-10(5): 666-673

Pinheiro H, Botteron F, Rech C, Schuch L, Camargo R F, Hey H L, Grundling H A and Pinheiro J R 2002 Space vector modulation for voltage-source inverters: A unified approach. In: Proceedings of 28th Annual Conference of Industrial Electronics Society, vol. 1, pp. 23-29

Ramkumar S, Jeevananthan S and Kamaraj V 2009 Novel amplitude modulated triangular carrier gain linearization technique for SPWM inverter. Serbian J. Electr. Eng. (SJEE) 6(2): 239-252

Reza Salehi, Naeem Farolhnia, Mehrdad Abedi and Seyed Hamid Fathi 2011 Elimination of low order harmonic in multilevel inverters using genetic algorithm. J. Power Electron. 11(2): 132-140

Rodriguez J, Jih-Sheng Lai and Fang Zheng Peng 2002 Multilevel inverters: A survey of topologies, controls, and applications. IEEE Trans. Ind. Electron. 49(4): 724-738 
Said Barkati, Lofti Baghli, El Madjid Berkouk and Mohammed-Seghir Boucherit 2008 Harmonic elimination in diode-clamped multilevel inverter using evolutionary algorithms. J. Electr. Power Syst. Res. 78(10): 1736-1746

Samadi A and Farhangi S 2007 A novel optimization methods for solving harmonic elimination equations. In: Proceedings of $7^{\text {th }}$ International Conference on Power Electronics, pp. 180-185

Sangeetha S and Jeevananthan S 2014 Resultant theory and jenkins-traub algorithm Based SHEPWM using assimilated software environment for a seven level VSI. Asian Power Electron. J. 8(1): 1-9

Schutten M J and Torrey D A 1995 Genetic algorithms for control of power converters. In: Proceedings of Power Electronics Specialists Conference pp. 1321-1326

Spears W M and DeJong K 1991 An analysis of multi-point crossover. In: Rawlins G J E (Ed.) Foundations of genetic algorithms. Morgan Kaufman publishers, pp. 301-315

Sundareswaran K, Jayant K and Shanavas T N 2007 Inverter harmonic elimination through a colony of continuously exploring ants. IEEE Trans. Ind. Electron. 54(5): 2558-2565

Tolbert L M, Fang Zheng Peng and Habetler T G 1999 Multilevel converters for large electric drives. IEEE Trans. Ind. Appl. 35(1): 36-44

Whitley D 1989 The genitor algorithm and selection pressure: why rank-based allocation of reproductive trials is best. In: Proceedings of $3^{\text {rd }}$ International Conference on Genetic Algorithms, pp. 116-121

Yamada T and Nakano R 1997 Genetic algorithms for job-shop scheduling problems. In: Proceedings of Modern Heuristic for Decision Support, pp. 67-81

Zhong Du, Leon M Tolbert and John N Chiasson 2004 Active harmonic elimination in multilevel converters using FPGA control. IEEE Proc. Comput. Power Electron. pp. 127-132

Zhong Du, Leon M Tolbert and John N Chiasson 2006 Active harmonic elimination for multilevel converters. IEEE Trans. Power Electron. 21(2): 459-469

Zhong Du, Leon M Tolbert, Chiasson J N and Ozpineci B 2008 Reduced switching-frequency active harmonic elimination for multilevel converters. IEEE Trans. Ind. Electron 55(4): 1761-1770 